\title{
Application of 3D graphic software and GIS in visual impact assessment of high-voltage overhead transmission lines
}

\author{
Mariusz Sojka ${ }^{1, *}$, Rafał Wróżyński ${ }^{1}$, and Krzysztof Pyszny ${ }^{2}$ \\ ${ }^{1}$ Faculty of Environmental Engineering and Spatial Management, Poznań University of Life Sciences, ul. Piątkowska 94, 60-649 Poznań, \\ Poland \\ ${ }^{2}$ EnviMap, ul. Piątkowska 118/31, 60-649 Poznań, Poland
}

\begin{abstract}
The paper presents the possibility of using GIS tools and 3D graphic software to assess the impact of high voltage overhead transmission lines on the landscape. The paper uses a digital elevation model developed on the basis of airborne laser scanning data. In addition, potential locations and high voltage overhead transmission lines tower heights have been used. The Viewshed tool available in the ArcGIS software made it possible to calculate the visibility range of tower. To limit the spatial range of the analysis 3D simulations were carried out in Blender version 2.79 . Visibility range analysis was performed in the range from $250 \mathrm{~m}$ to $3000 \mathrm{~m}$ in steps of $250 \mathrm{~m}$. The render analysis in relation to the percentage of the area occupied by the HVOTLs tower in the total field of view, allowed to limit the range of the analysis. Calculations have shown that the range of the HVOTLs tower impact assessment should be limited to $2 \mathrm{~km}$. The very strong and strong visual impact of the tower range from 0 to $250 \mathrm{~m}$. In contrast, there is a significant impact between $251 \mathrm{~m}$ and $750 \mathrm{~m}$ and a moderate and weak impact above $750 \mathrm{~m}$.
\end{abstract}

\section{Introduction}

The development of the energy sector in Europe, linked to the use of renewable energy sources also involves investments in transmission networks [1]. The expansion and modification of high voltage overhead transmission lines (HVOTLs) is a key element of the energy transition [2]. The location of HVOTLs is often subject to public opposition [3]. Most often their potential health effects linked to electric and magnetic fields (EMF) and visual impacts (VI) are taken into account [3]. Power lines are often controversial, due to their perceived negative impacts on rural landscapes [3]. Tempesta et al. [4] indicated that the HVOTLs have major impact on landscape quality. Therefore, before starting the construction of HVOTLs it is necessary to conduct detailed analyses of their potential VI on the landscape. The VI of HVOTLs on the landscape is one of the most subjective factors that can influence the choice of their location. The VI of a HVOTLs depends on observer's preferences, distance from the observer, relief, land cover and atmospheric conditions. So far, wind turbines (WT) have been of interest in terms of VI on the landscape. For WT, several quantitative methods have been developed to assess their VI on the landscape. These methods use the potential of GIS tools and digital elevation models (DEM). The most useful DEM are based on airborne laser scanning data [5]. DEM models can be updated with photogrammetric methods [6]. It is possible to use the methods applied for WT in the assessment of VI on the landscape of HVOTLs. One of the most recent in this respect is the method developed by Wróżyński et al. [7], in which the possibilities of GIS tools and 3D Blender graphics were used. The aim of this study was to modify the method to quantify visual impact assessment of WT proposed by Wróżyński et al. [7] to visual impact assessment of the HVOTLs. The method is based on GIS tools, Digital Surface Model (DSM) and rendered images of HVOTLs developed in 3D graphic software Blender.

\section{Materials and methods}

The assessment of the impact on the landscape of HVOTLs was made according to the modify methodology proposed by Wróżyński et al. (2016). The analysis was based on the DEM (DEM), with a resolution of $1 \mathrm{~m}$, developed on the basis of data from airborne laser scanning LiDAR obtained from the Central Office of Geodesy and Cartography in Poland. In the first stage, the DEM model was pre-processed for analysis using ArcGIS and Global Mapper software. In the second stage, the DEM was supplemented with land cover elements, using data from the Topographic Objects Database (TOD). The building height was determined by multiplying the number of storeys by the height of one storey, which was set at the level of $3 \mathrm{~m}$. The height of natural forms of land cover: forests and trees was determined on the basis of information contained in the

"Corresponding author: masojka@up.poznan.pl 
Data Bank on Forests of the General Directorate of State Forests. In this way, a digital surface model (DSM) was developed. Next, a vector layer (shapefile) was created, on which the location of the HVOTL towers was indicated. The height of the HVOTLs towers was assumed to be $36.6 \mathrm{~m}$. The visibility range of the towers was assessed using the Viewshed tool available in the ArcGIS software 10.5.1. The result of the analysis was a raster map with a resolution of $10 \mathrm{~m}$, on which the value of 0 means that the HVOTLs tower is not visible and 1 means that the tower is visible. The assessment of the extent of tower visibility was based on a 3 -fold repetition of the Viewshed analysis. In the following steps, the height of the tower was assumed to be $12.2 \mathrm{~m}, 24.4 \mathrm{~m}$ and $36.6 \mathrm{~m}$ (Fig. 1). In this way, 3 raster maps were obtained. In order to determine the visibility range of the tower, the results were summed up using the Raster Calculator tool available in ArcGIS. As a result of this procedure, a raster map with values ranging from 0 to 3 was obtained. These values determine the visibility of the HVOTLs tower. When the value is 3 - means that the whole tower is visible, 2 - means that $24.4 \mathrm{~m}$ of the tower is visible, 1 - means that $12.2 \mathrm{~m}$ of the tower is visible, 0 - means that the tower is not visible.

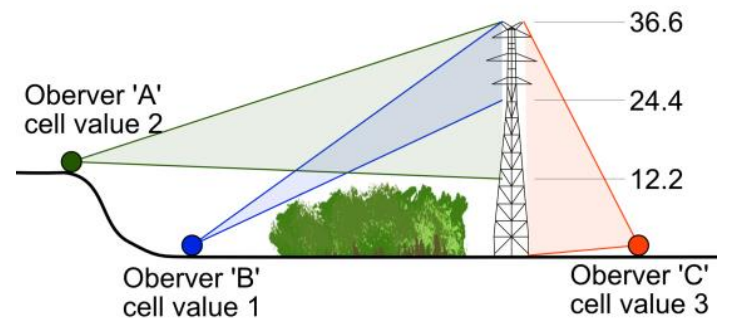

Fig. 1. Procedure used for the HVOTLs tower visibility range determination

To limit the spatial range of the analysis 3D simulations were carried out in Blender version 2.79. Blender is professional free software allowing creating visualizations and $3 \mathrm{D}$ animations. Blender was used to simulate the visibility of the tower from a frontal perspective. During the simulation, the most unfavourable variant in terms of visibility was assumed: the column is black and the background is white (Fig. 2).

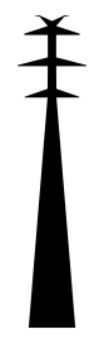

Fig. 2. HVOTLs tower model

For each of the HVOTLs tower visibility variants there are renderings (photos taken in Blender) in the range from $250 \mathrm{~m}$ to $3000 \mathrm{~m}$, with a step by step of $250 \mathrm{~m}$. During the simulation, changes in the visibility range of the tower from 12.2 to $36.6 \mathrm{~m}$ were taken into account (Fig. 3).

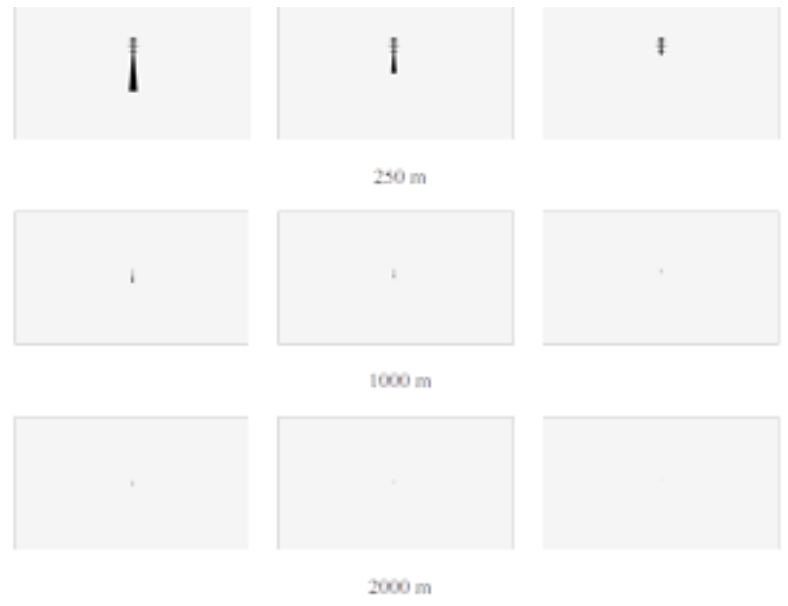

Fig. 3. The visible size of a HVOTLs tower of 12.2, 24.4 and $36.6 \mathrm{~m}$ from the top, as seen from the distance of $250 \mathrm{~m}, 1000$ $\mathrm{m}$ and $2000 \mathrm{~m}$

Renders have been developed with resolution of 1920x1080 pixels, assuming virtual camera with matrix size corresponding to full frame $(36 \times 24 \mathrm{~mm})$ and focal length of $50 \mathrm{~mm}$. Based on the renders, the percentage of the area occupied by the tower in relation to the total view field was determined. Blender GIS addon plugin was able to import raster and vector files from GIS environment to Blender environment. This allowed to build a three-dimensional realistic model of the analysed area on the basis of DEM, shape files and to place a HVOTLs tower model in it (Fig. 4)

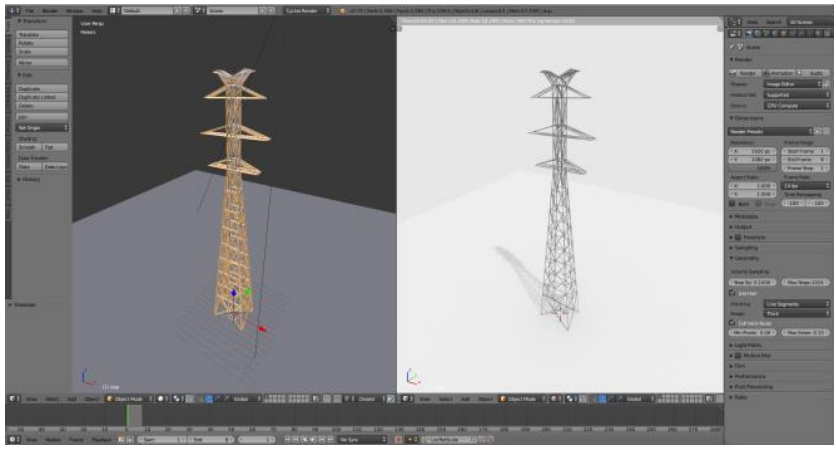

Fig. 4. The model of the HVOTLs tower developed in the Blender program

A five-step scale has been used to assess the impact of the HVOTLs tower on the landscape (Table 1) (Wróżyński et al. [8]).

Table 1: Scale of Impact Assessment of the HVOTLs tower on Landscape [8]

\begin{tabular}{|l|l|l|}
\hline $\begin{array}{l}\text { Percentage of the tower } \\
\text { in relation to the field of }\end{array}$ & Scale & Visual impact \\
\hline
\end{tabular}




\begin{tabular}{|c|c|c|}
\hline view (\%) & & \\
\hline$>1.02$ & 5 & very strong \\
\hline $0.27-1.01$ & 4 & strong \\
\hline $0.07-0.26$ & 3 & significant \\
\hline $0.04-0.06$ & 2 & moderate \\
\hline $0.01-0.03$ & 1 & weak \\
\hline
\end{tabular}

\section{Results and discussion}

Application of the methodology using GIS and 3D graphics tools to visual impact assess of HVOTLs on the landscape was presented on the example of the designed $110 \mathrm{kV}$ line Ogrodzieniec - Łasin in central Poland. The length of the designed HVOTLs is approx. $24.2 \mathrm{~km}$.

In the first stage, we prepared renders - a black HVOTLs tower on a white background, from which the percentage of the tower in the total view field was calculated. It was assumed that from each location the tower is visible in the frontal position and visibility is not disturbed by weather conditions. This is the most unfavourable variant of tower visibility. The renders analysis in relation to the percentage of the area occupied by the HVOTLs tower in the total field of view, allowed to limit the extent of the analysis. It was assumed that when the tower on the render occupies less than $0.02 \%$, its visibility is very limited. It has thus been demonstrated that the analysis of the VI of the HVOTLs tower on the landscape should be limited to $2 \mathrm{~km}$. Outside this range, the tower is considered to be visible, but the VI on the landscape is insignificant.

The results show that the extent of the VI is gradually decreasing. This is due to the observer's distance from the HVOTLs tower and the range of visibility. The percentage of the column in the total field of view depending on the range of visibility and distance is shown in Table 2.

Table 2: Percentage area of the wind turbine on rendered images

\begin{tabular}{|c|c|c|c|}
\hline \multirow{2}{*}{ Distance $(\mathrm{m})$} & \multicolumn{3}{|c|}{ Visibility range (m) } \\
\cline { 2 - 4 } & 12.2 & 24.4 & 36.6 \\
\hline 250 & 0.21 & 0.43 & 0.83 \\
\hline 500 & 0.06 & 0.11 & 0.21 \\
\hline 750 & 0.03 & 0.05 & 0.10 \\
\hline 1000 & 0.02 & 0.03 & 0.06 \\
\hline 1250 & 0.01 & 0.02 & 0.04 \\
\hline 1500 & 0.01 & 0.02 & 0.03 \\
\hline 1750 & 0.01 & 0.01 & 0.02 \\
\hline 2000 & 0.01 & 0.01 & 0.02 \\
\hline
\end{tabular}

Calculations have shown that when the whole tower is visible, the range of a very strong and strong impact does not exceed $250 \mathrm{~m}$ (red and orange). Moreover in the range from 251 to $750 \mathrm{~m}$ is significant (yellow) and above $750 \mathrm{~m}$ moderate and weak (dark and light green) (Figure 5). If the tower is hidden by trees or buildings, the range of its VI is weak (Table 2).

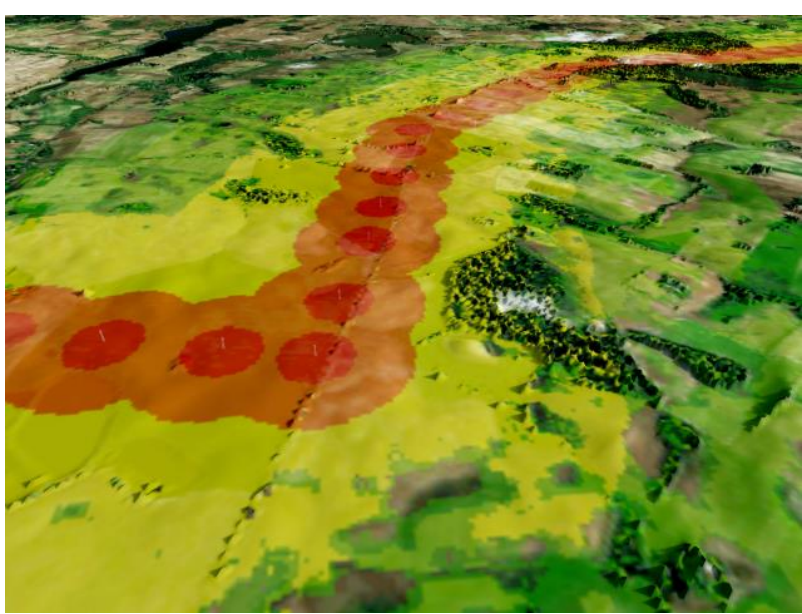

Fig. 5. Range and visual impact on the landscape of the planned HVOTLs towers

The results of the analysis show that within HVOTLs there are places where the columns are invisible or their impact is insignificant. This is due to the location of the observer in relation to the tower and the range of his visibility. Examples of visualizations showing the location of HVOTLs tower within the range of wind turbines are presented in Figure 6.

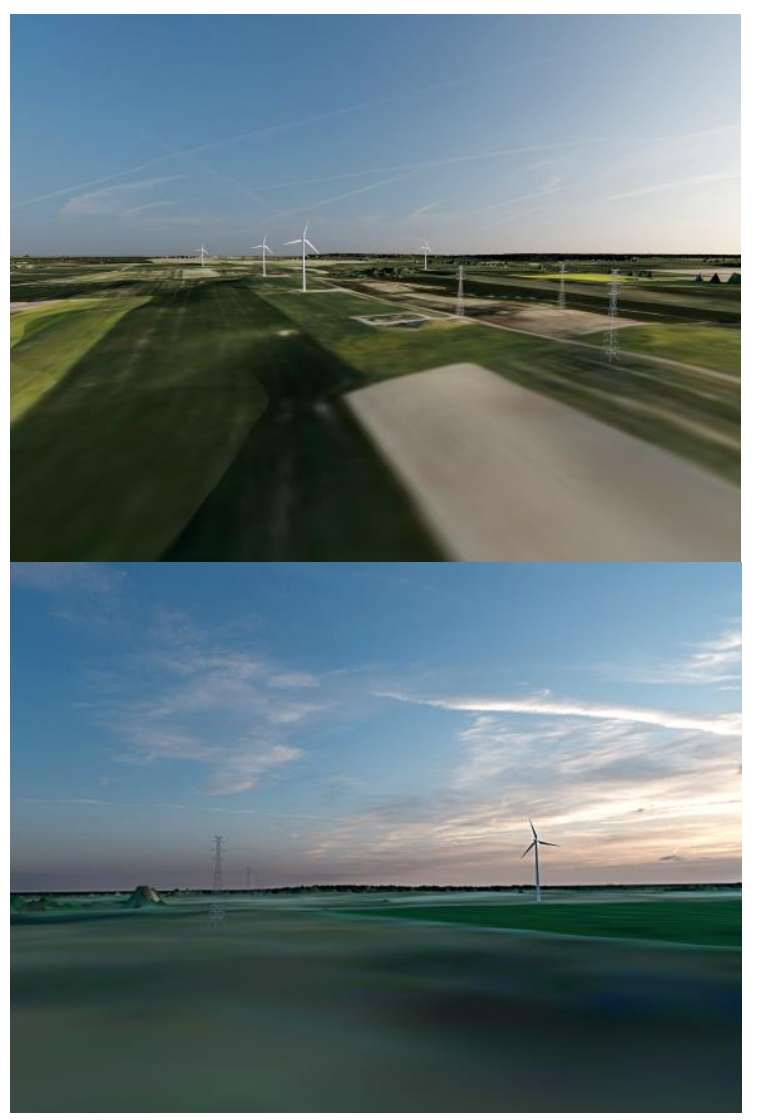

Fig. 6. Results of 3D visualization from Blender

It should be noted that the landscape impact assessments are subjective. As regards the lack of reference methods, it is not possible to determine the extent of significant negative impact on the landscape. The scale of assessment adopted for Wróżyński et al. [8] was the first 
attempt to quantify the assessment of the impact on the landscape and is currently under discussion.

\section{Conclusions}

The analyses carried out have shown that:

- available GIS and 3D graphics tools allow to assess the visual impact of high voltage overhead transmission lines on the landscape,

- the range of the visual impact analysis of $36.6 \mathrm{~m}$ high HVOTLs tower on the landscape should be limited to $2 \mathrm{~km}$,

- the extent of the very strong and strong impact of $36.6 \mathrm{~m}$ high HVOTLs tower on the landscape is approximately $250 \mathrm{~m}$,

- GIS tools in connection with 3D graphics tools should be used to identify the optimal HVOTLs location.

\section{Acknowledgements}

Publication is funded by the Polish National Agency for Academic Exchange under the International Academic Partnerships Programme from the project „Organization of the 9th International Scientific and Technical Conference entitled Environmental Engineering, Photogrammetry, Geoinformatics - Modern Technologies and Development Perspectives".

\section{References}

1. Ø. Aas, P. Devine-Wright, T. Tangeland, S. Batel, A. Ruud. ERSS, 2, 30-37 (2014)

2. P. Lienert, B. Suetterlin, M. Siegrist, ENERG POLICY, 87 573-583 (2015)

3. M. Cotton, P. Devine-Wright. J ENVIRON PLANN MAN, 56(8) 1225-1245 (2013)

4. T. Tempesta, D. Vecchiato, P. Girardi (2014). Landsc Urban Plan, 126 53-64 (2014)

5. Z. Walczak, M. Sojka., R. Wróżyński, I. Laks. Water, 8(6) (2016)

6. R. Wróżyński, K. Pyszny, M. Sojka, C. Przybyła, S. Murat-Błażejewska. OPEN GEOSCI 9 281-294 (2017)

7. R. Wróżyński, M. Sojka, K. Pyszny. RENEW ENERG, 96 part A 625-635 (2016)

8. R. Wróżyński, M. Sojka, K. Pyszny. GIS and spatial data in environmental impact assessments (in Polish), 81, Wyd. Nauk. UAM 105-120 (2017). http://hdl.handle.net/10593/21677 